\title{
Adaptation capacity of a landslide early warning system to climate change: numerical modeling for the Combeima region in Colombia
}

\author{
Khabarov, N. ${ }^{1}$, Huggel, C., ${ }^{2}$ Obersteiner, M. ${ }^{1}$, Ramírez, J. M. ${ }^{3}$
}

Received: 28/01/2011 / Accepted: 16/06/2011 / Published online: 13/12/2011

\begin{abstract}
Mountain regions are typically characterized by rugged terrain which is susceptible to different types of landslides during high-intensity precipitation. Landslides account for billions of dollars of damage and many casualties, and are expected to increase in frequency in the future due to a projected increase of precipitation intensity. Early warning systems (EWS) are thought to be a primary tool for related disaster risk reduction and climate change adaptation to extreme climatic events and hydrometeorological hazards, including landslides. EWS are highly complex systems, and it is therefore difficult to understand the effect of the different components and changing conditions on the overall performance, ultimately being expressed as human lives saved or structural damage reduced.

In this paper we utilize a numerical model using 6 hour rainfall data as basic input. A threshold function based on a rainfall-intensity/duration relation was applied as a decision criterion for evacuation. Correct evacuation was assessed with a 'true' reference rainfall dataset versus a dataset of artificially reduced quality imitating the observation system component. Performance of the EWS using these rainfall datasets was expressed in monetary terms (i.e. damage related to false and correct evacuation).

We applied this model to a landslide EWS in Colombia that has been implemented in recent years within a disaster prevention project. We evaluated the EWS against rainfall data with artificially introduced error and computed with multiple model runs the probabilistic damage functions depending on rainfall error. Then we modified the original precipitation pattern to reflect possible climatic changes e.g. change in annual precipitation as well as change in precipitation intensity with annual values remaining constant. We let the EWS model adapt for changed conditions to function optimally. Our results show that for the same errors in rainfall measurements the system's performance degrades with expected changing climatic conditions. The obtained results suggest that EWS cannot internally adapt to climate change and require exogenous adaptive measures to avoid increase in overall damage.

The model represents a first attempt to integrally simulate and evaluate EWS under future possible climatic pressures. Future work will concentrate on refining model components and spatially explicit climate scenarios.
\end{abstract}

Key wordsLandslides; Early Warning Systems; Climate Change; Uncertainties; Integrated Modeling.

\footnotetext{
${ }^{1}$ International Institute for Applied Systems Analysis, Laxenburg, Austria

${ }^{2}$ Department of Geography, University of Zurich, Zurich, Switzerland

IIndependent Hydrology Consultant, Bogota, Colombia
} 


\section{Introduction}

Early warning systems (EWS) are important means of risk reduction in the context of natural disasters. EWS have been developed for a number of different hazards including tsunamis, volcanoes, snow avalanches, landslides and others (Zschau and Küppers 2003). EWS commonly consist of several interlinked components, such as sensors measuring relevant physical parameters, telecommunication equipment, monitoring centers, and organizational structures disseminating publicly understandable information. The awareness and knowledge of people exposed to a hazard are very important for an adequate response to an early warning. Due to their multi-component structure EWS have been recognized as highly complex systems ultimately characterized by a tricky interaction between technical instruments and human behavior (Sorensen 2000; Basher 2006). Due to the uncertainties related to different parts of an EWS its systematic evaluation is rather complicated.

We present here an approach to numerically model a landslide EWS that enables us to systematically assess possible impacts of climatically related changes on a EWS performance. Further we focus our analysis on the adaptation capacity of a EWS that depends on possible sensor related modifications and improvements in decision making rules.

We developed our model based on a recently implemented landslide EWS in Colombia, which is currently being calibrated and adjusted. Landslides are notorious in Colombia due to the rough topography and tropical rainfall conditions and thus are a major hazard in many regions of the country. The Combeima region, Tolima province, is a particularly exposed area, including several population centers along the valley and the regional capital Ibagué (ca. 0.5 million inhabitants). Hundreds of people have been killed by landslides and debris flows in the past. According to projected precipitation increase due to climate change (Christensen et al. 2007) and taking into account that rainfalls are the main trigger of landslides in this area, the situation is likely to worsen in the future.

The integrated EWS model described in this paper represents a novel approach and we therefore had to simplify several components of the real EWS and also use simplified climate change scenarios. Nevertheless, it should be able to provide indications on how the EWS in the Combeima region could be improved in the future. Although the model is driven by data from this case study, the model concept is designed sufficiently open for adaptation to other landslide EWS, and results should also have some relevance for a broader context.

\section{EWS in Colombia}

\subsection{Study area}

The Combeima river is one of the major drainages of the Nevado del Tolima Volcano, located in central Colombia in the Cordillera Central. The Combeima valley extends from the regional capital Ibagué ( 500,000 inhabitants) at $1250 \mathrm{~m}$ asl along more than $20 \mathrm{~km}$ to about $2500 \mathrm{~m}$ asl before it abruptly rises to the summit of Nevado del Tolima at $5200 \mathrm{~m}$ asl. Several towns populate the Combeima valley, with a total of about 5500 people (Fig. 1). 


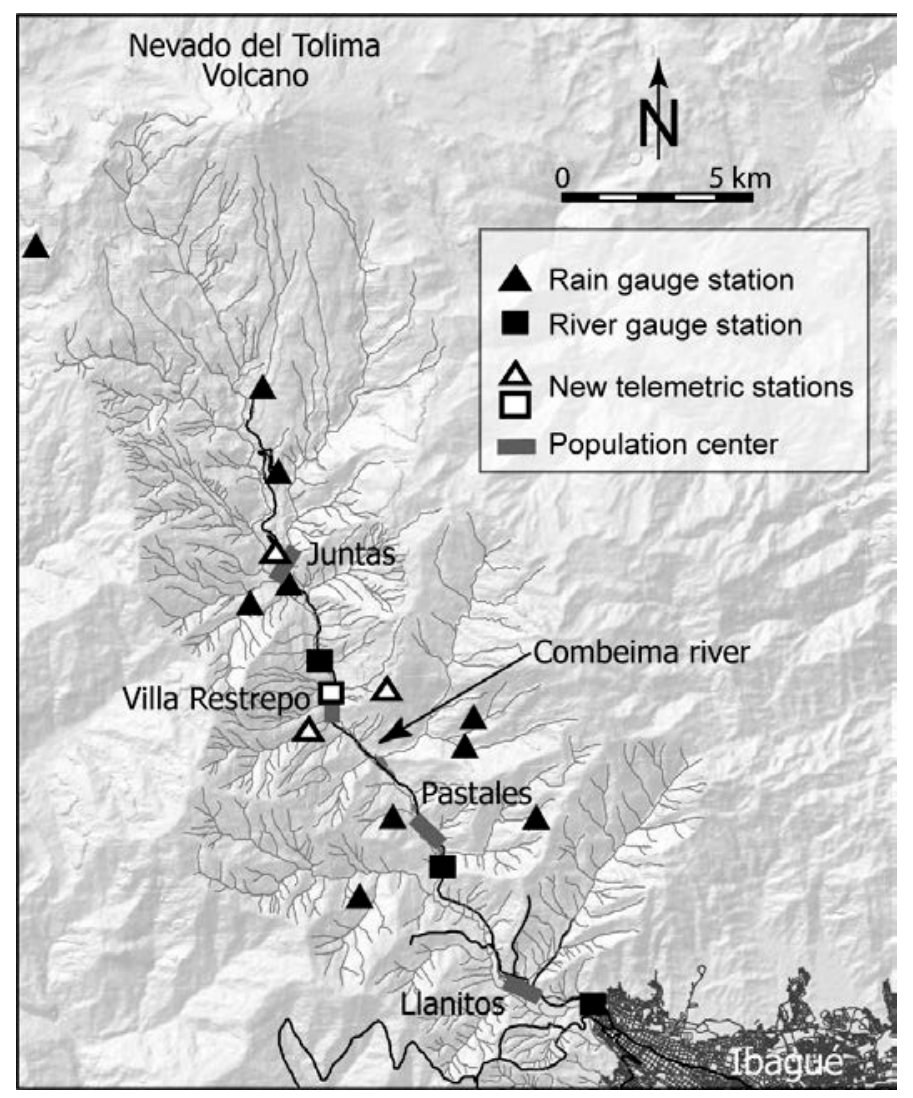

Figure 1. Map and stream flow system of the Combeima valley. Triangles indicate locations with rainfall stations (only partly operational), with white triangles referring to new telemetric rainfall stations that form part of the landslide EWS.

The area is characterized by very steep topography and dense vegetation. Mean annual rainfall varies between 1500 and $2500 \mathrm{~mm}$. The geology is dominated by the volcanic activity of the area. Two major active volcanoes, Tolima and Machín volcano, are located within distances of 10-20 km and have repeatedly erupted during the Holocene (Thouret et al. 1995). As a consequence, the soils of the steep slopes of the Combeima valley are often characterized by a high content of ash and other volcanic products, partly with underlying metamorphic rocks. Geotechnical soil parameters are typically characterized by poor slope stability. Steep topography, high rainfall intensities and poor slope stability make the Combeima valley particularly vulnerable to landslides. The landslides typically start as shallow slope failures in the middle and upper reaches of the catchments, and develop into rapid debris flows in the steep gullies. Flow discharge can be extremely high, up to several hundred cubic meters, as field work has shown. Due to the high energy of the landslides, the impact on populated areas in the Combeima valley is violent and highly destructive. In fact, people have suffered from landslide disasters for many decades and several hundred people have been in landslide disasters in the past decades (Godoy et al. 1997). Most recently, landslide disasters occurred in the Combeima valley in 2006 and 2009, with serious damage and destruction to buildings and infrastructure but fortunately without any casualties (Fig. 2). At one of the villages, Villa Restrepo, almost exactly the same areas were impacted by the 2006 and 2009 landslides, and as a consequence suffered from a similar level of damage. As a reaction of the high frequency of landslides, some the buildings were abandoned after 2009 event. 


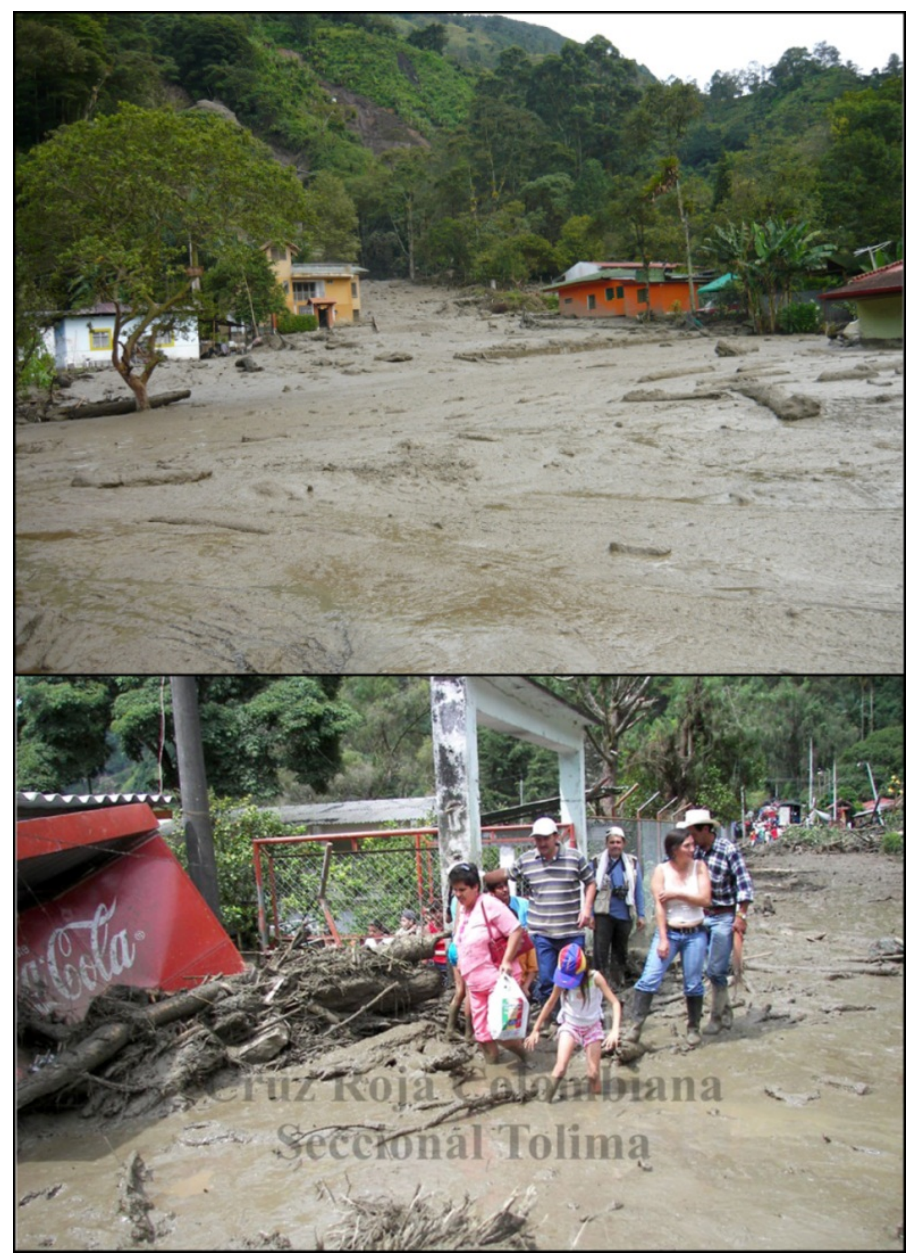

Figure 2. Recent landslide disasters in the Combeima valley: upper picture: houses destroyed and severely affected by the July 2009 landslide in Villa Restrepo; lower picture: local people after the similarly destructive landslide in June 2006 at the same location (photo courtesy of the Tolima Regional Disaster Prevention Committee and the Colombian Red Cross).

\subsection{Rainfall records}

Rainfall measuring stations are a key component of a landslide EWS. In the Combeima valley, the first rainfall station was installed in the late 1950s. The bulk of stations existing today came into operation in the 1980s. Stations are operated by the Colombian Institute of Hydrology, Meteorology and Environmental Studies (IDEAM) and data are centrally managed in Bogotá. The IDEAM network currently includes ten stations in the Combeima valley (Fig. 1). The rainfall recording is continuous on daily charts, which can be evaluated to intervals as low as 15 minutes. Based on the IDEAM rainfall data, rainfall intensity-duration curves have been calculated, indicating that for a duration of 60 min the 10-year return period intensity may vary between 40 and $60 \mathrm{~mm} / \mathrm{h}$ (Huggel et al., 2010). Between 2007 and 2010, four telemetric stations were installed which can be programmed to transmit measured data when a rainfall increment occurs (i.e. $0.2 \mathrm{~mm}$ ) or at a fixed time interval. Although the older rainfall gauges in the Combeima had a comparably high density, their use for a landslide EWS was limited because most of the stations are not telemetric (charts data are collected about every month) and thus not providing the necessary real-time data. The historical rainfall data have been used to analyze antecedent rainfall conditions for a number of documented landslides and define warning levels for the EWS (Huggel et al., 
2010).

\subsection{EWS related challenges}

The history of landslide events in the Combeima valley entails the necessity of disaster risk reduction. Structural protection measures are often not feasible due to financial restrictions, therefore organizational and preparedness measures including EWS are in the focus of risk reduction strategy in that area.

An appropriate implementation and operation of a landslide EWS is a complex task and only few examples can be found worldwide. A number of physical models were developed that describe the mechanics of material strength, gravitational stress, pore-fluid pressure and external forces (e.g. Iverson et al. 1997; Petley et al. 2005). A major drawback to apply physical-mechanical models for landslide EWS is the great variability of properties of soil and earth materials and slope conditions that make the prediction of when and where a landslide occurs very difficult. Therefore, empirical relations between rainfall duration or intensity and landslide initiation are typically applied for EWS. These relations need to be established by a record of landslide-triggering rainfall events. Several relations have been presented for different regions worldwide (Glade et al., 2000; Guzzetti et al. 2008), but are mostly lacking for Colombia so far (Terlien 1998).

The spatial variability of rainfall and incomplete event description induce an uncertainty into the rainfall-landslide triggering threshold. The large variability of antecedent rainfall observed for past landslide events in the Combeima valley makes the definition of warning thresholds difficult. Based on the analysis of more than 50 landslide events, it has been found that the 30-day antecedent rainfall amount could vary between $100 \mathrm{~mm}$ and $350 \mathrm{~mm}$ (Huggel et al. 2010). To reduce the uncertainties, the newly installed rainfall stations were equipped with geophones that transmit increasing debris flow activity in the stream channels. Additional information is provided by local observers that timely report potentially landslide-producing situations to the EWS center in Ibagué (Fig. 1) where all available information is analyzed 24 hours a day.

The EWS is only successful if it is also accepted, understood, and used by the local population. Even though the technical side of the EWS is complex, the greatest potential for failure exists if the local population is inadequately prepared for emergencies. Therefore, preparedness and social programs have been carried out in the Combeima region. These studies are, however, beyond the scope of this paper, and will not be discussed here in further detail.

\section{Modeling climate change impacts}

\subsection{A numerical EWS model}

Here we shortly present a mathematical model based on stochastic optimization approach developed for the Combeima region (Huggel et al. 2010). The model is basically mimicking different components of a landslide EWS including rainfall observations with relevant observation errors, triggering thresholds, evacuation rules based on optimization procedures, and ultimately loss calculation. We further use that model for assessment of climate change impacts.

Although there exists a rainfall record from several rain gauges in the Combeima valley (as outlined above), there are a number of limitations regarding complete data series over many years at temporal resolutions better than daily ones. Therefore, instead of local rain gauges we used ERA-40 reanalysis rainfall data (Uppala et al. 2005) from a grid cell closest to the Combeima valley (Huggel et al. 2010). The spatial resolution of the rainfall data is $2.5^{\circ}$, the temporal resolution is 6 hours.

A landslide triggering threshold is described in terms of the rainfall intensity I $[\mathrm{mm} / \mathrm{h}]$ and duration D $[\mathrm{h}]$ involving some empirical parameters $\mathrm{a}$ and $\mathrm{b}$ : 


$$
I=a D^{b}
$$

In absence of any regional or local threshold available for our study region in Colombia, we used the Caine (Caine 1980) global threshold $(\mathrm{a}=14.82, \mathrm{~b}=-0.39)$. In our modeling exercise we consider a time period of 10 years (1991-2000) split into smaller intervals of 6 hours each. The triggering threshold function $L(i)$ is binary-valued and has the form

$$
L(i)=\left\{\begin{array}{l}
1, \text { if } \max _{0 \leq j \leq 19}\left(I_{i j}-\tilde{I}_{j}\right) \geq 0, \\
0, \text { else. }
\end{array}\right.
$$

Here $\tilde{I}_{j}=14.82[6(j+1)]^{-0.39}, j=0, \ldots ., 19$ are triggering intensities derived from (1) for time intervals ranging from 6 to 120 hours, $i \geq 20$ is the number of a 6-hour interval within the whole 10 -year time period. Values $\left\{I_{i j}\right\}$ are calculated intensities: $I_{i j}=\frac{1}{6(j+1)} \sum_{k=0}^{j} r_{(i-k)}$ for rainfall data $\left\{r_{i}\right\}$. The value 1 of the function $L(i)$ represents a landslide occurrence in the $i^{\text {th }}$ time frame, whereas value 0 means no landslide in the $i^{\text {th }}$ time frame.

In (2) exact values of rainfall $\left\{r_{i}\right\}$ are used to calculate intensities $I_{i j}$. In reality the exact precipitation is not known, instead its value is measured with some error. We model rainfall measurement error for each time frame $i$ by means of a random value generation distributed uniformly in the interval $\left[r_{i}-\varepsilon r_{i}, r_{i}+\varepsilon r_{i}\right]$ where $\varepsilon$ is a constant rainfall measurement error (RME) with its value fixed in the interval $[0,0.3]$ for the purposes of numerical simulations.

The evacuation threshold function is based on (2) and defined by the following expression

$$
V(i, \lambda)=\left\{\begin{array}{l}
1, \text { if } \max _{0 \leq j \leq 19}\left(\hat{I}_{i j}-\lambda \tilde{I}_{j}\right) \geq 0 \\
0, \text { else. }
\end{array}\right.
$$

where $\lambda \in(0,1)$ is a correction coefficient to be determined later and $\left\{\hat{I}_{i j}\right\}$ are intensities calculated in the same way as $\left\{I_{i j}\right\}$, but for observed rainfall

$$
\hat{r}_{i} \sim U\left(r_{i}-\varepsilon r_{i}, r_{i}+\varepsilon r_{i}\right),
$$

where $U$ denotes a uniform distribution within the specified interval. Knowing details of a particular rainfall measurement system, the suggested simplified measurement error modeling approach can be adjusted by switching to a skewed distribution. Because of the reasonable sensitivity of the model to the rainfall measurement error presented below (see e.g. Figure 6), a highly precise modeling of a rainfall measurement error is not a critical issue in our model setup.

We define the loss function in the following form: 


$$
F(\lambda)=\sum_{i} L(i)[1-V(i, \lambda)] d_{i}+L(i) b_{i}+V(i, \lambda) u
$$

Here $L(i)$ is defined in (2); $V(i, \lambda)$ is defined in (3); ${ }^{d}$ is a random value describing the damage associated with loss of life incurred only in case if landslide occurs and no evacuation was performed; $b_{i}$ is a random value describing the damage to the buildings and infrastructure; $u$ is the cost of evacuation (constant value). The loss function $F(\lambda)$ is a random variable depending on the evacuation threshold correction coefficient $\lambda$.

The evacuation threshold (3) depends on adjustment coefficient $\lambda \in(0,1)$ which is an unknown parameter subject to optimization. The objective of the optimization procedure is to minimize expected losses:

$$
\min _{\lambda} \mathrm{E}[F(\lambda)]
$$

here $\mathrm{E}[\cdot]$ denotes the expectation of a random value. We further fix evacuation cost $u=10,000$, the total expected loss of life per one landslide $\mathrm{E}\left[d_{i}\right]=5,000,000$ (constant for all $i$ ) and assume $\mathrm{E}\left[b_{i}\right]$ is some constant (for all $i$ ). The aforementioned numbers can be considered in US Dollars and represent estimates for a typical situation in the Combeima valley.

We numerically solve the stochastic optimization problem (6) for all discrete values of RME $\varepsilon$ in the interval $[0,0.3]$ with a step of 0.05 . To find an approximate solution, we produce 10,000 samples of rainfall observations for each of the 6-hours time frames within the whole 10-year period according to (4).

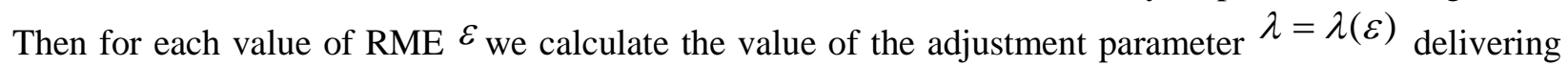
minimum expected losses.

Further discussion on model parameters, sensitivity with regard to introduced constants, and EWS performance can be found in (Huggel et al. 2010).

\subsection{Precipitation change scenarios}

For central Colombia, including our study area, the IPCC AR4 projects changes in precipitation of about $10-20 \%$ and 5-10\% for December to February and June to August, respectively, for 2090-95 with reference to 1980-99 (Christensen et al. 2007). However, with respect to extreme precipitation events, most recent regional climate model studies are ambiguous for the Cordillera Central of Colombia, indicating the possibility of both, an increasing or decreasing trend for the future (Marengo et al. 2009). The uncertainties in the precipitation change projection lead to the necessity for consideration of a full range of possible scenarios, with a variation interval of $\pm 20 \%$ of the baseline precipitation.

We run precipitation change scenarios for the future on the ERA-40 reference data. However, a precipitation change represented as a single number only (e.g. $+20 \%$ ) does not support a well defined damage assessment process, since it does not provide any information on a time structure of rainfalls, i.e. change in the magnitude and frequency of heavy precipitation events (those with high intensity over a relatively short time period). To cope with that issue, one may consider constructing scenarios with a special emphasis on heavy rainfalls and using them for analysis together with more simple scenarios where all the rainfall intensities are scaled equally independent of their intensity.

We fix a parameter $\Delta$ and compare two scenarios where (a) all rainfalls are scaled equally by $(1+\Delta)$ 
and (b) heavy rainfalls are scaled by $(1+\Delta)$ and small ones are scaled by $(1-\Delta)$ so that the total amount of yearly precipitation remains constant (this will make heavy rainfalls even bigger and small ones even smaller, or will make heavy rainfalls smaller and small ones bigger, depending on the sign of the parameter $\Delta$ ). It turned out that for the considered dataset and triggering threshold scenarios (a) and (b) deliver the same result in terms of the number of landslide occurrences (Fig. 3) and also in terms of expected damage (Fig. 4) for the full range of the scaling parameter $\Delta \in[-0.2,0.2]$. This outcome is not surprising since in the case study area landslides are triggered by extreme precipitation and both scenarios (a) and (b) do identically modify extreme rainfalls in the initial dataset: a small positive value of $\Delta$ does not transform small rainfalls into big ones in scenario (a); a relatively small negative value of delta does not transform small rainfalls into big ones in scenario (b). Based on this intermediate result we will not further distinguish between scenarios (a) and (b) in the subsequent text.

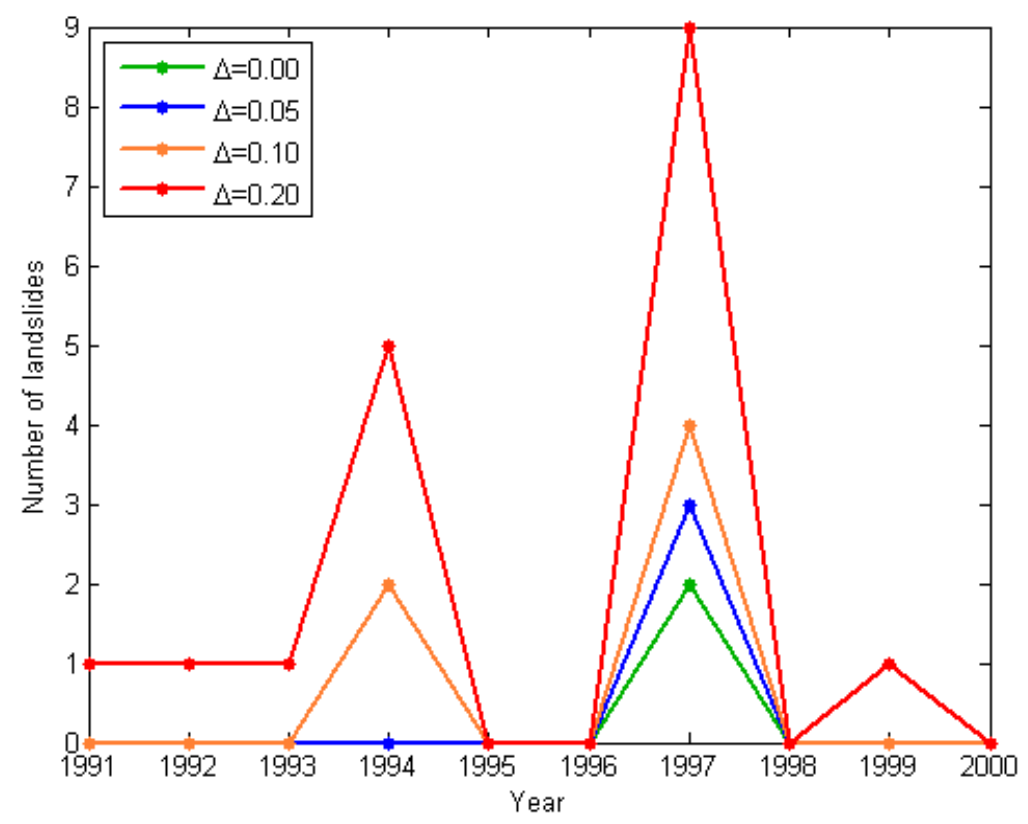

Figure 3.Modeled number of landslides for a changed precipitation. All rainfall intensities were scaled equally by $(1+\Delta)$ independently of the initial rainfall magnitude.

One drawback of the described simplified precipitation modeling approach is that it does not take into account spatial interdependency e.g. a rainfall increase in some areas may lead to decrease of precipitation in neighboring areas due to convective flows caused by a mountainous terrain. This does not however impact the landslide EWS model under consideration, since its dimensionless nature (one site is modeled only).

\subsection{EWS adaptation potential assessment}

The purpose of a EWS is to issue reliable warnings to allow population in the endangered area to be safely evacuated. Therefore, a EWS can prevent injuries and fatalities, yet it is not supposed nor can it in any way prevent damages to buildings and infrastructure caused by a landslide. When considering an adaptation capacity of a EWS to changing climatic conditions and related total loss expectations, for the purposes of measuring a EWS performance, it is necessary to distinguish between losses that can be prevented by a EWS and those that are beyond of its control. Otherwise, big expected change in 
infrastructural damage that is due to increased (or decreased) number of landslides will obscure the damage component being controlled by a EWS. For that reason, all expected losses estimated here (including those presented on Fig. 4) include evacuation costs, injuries and fatalities, and exclude damage to buildings and infrastructure.

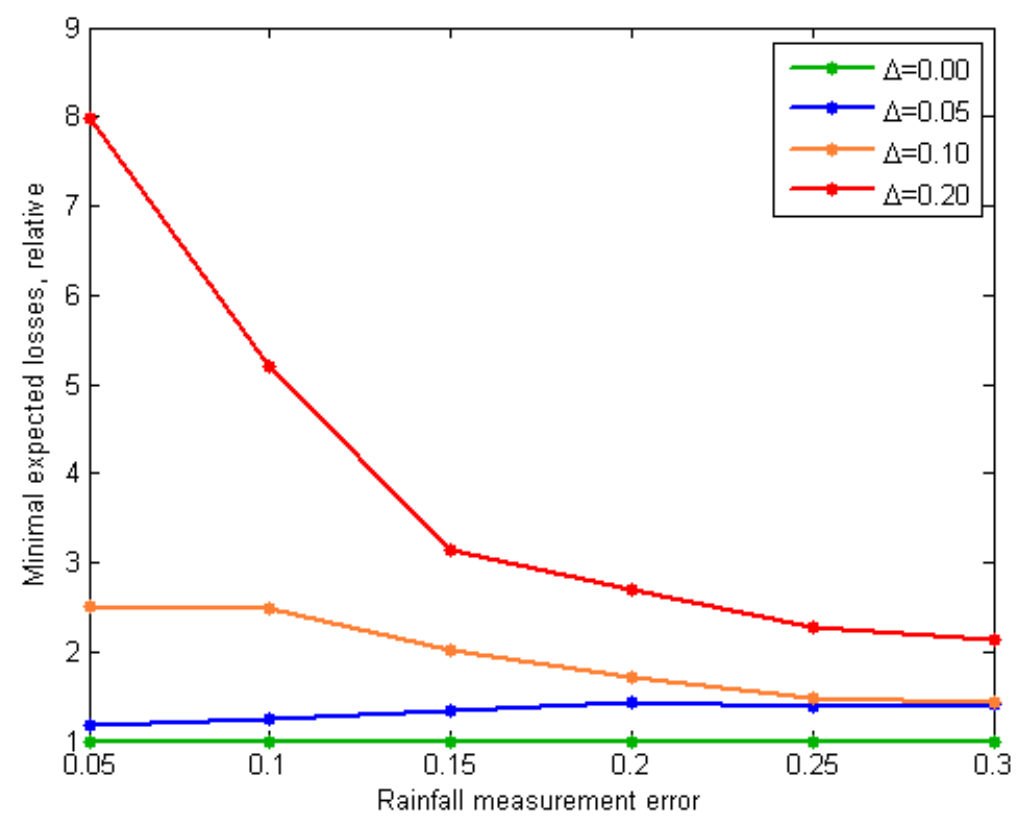

Figure 4. Expected damage (evacuation costs and fatalities) caused by landslides for different precipitation change levels $\Delta$ relative to a baseline. Evacuation thresholds were optimized individually for each value of $\Delta$ listed in the figure's legend.

Based on a rainfall dataset reflecting projected precipitation change scenario (different values of $\Delta$ ), the EWS model applies a rainfall intensity-duration threshold (2) to determine landslide occurrence and optimize evacuation threshold utilizing Monte-Carlo simulations for a fixed rainfall measurement error (different values of RME $\varepsilon$ ). The optimized evacuation thresholds ultimately translate both varied parameters $\Delta$ and $\varepsilon$ into a range of evacuation and damage scenarios derived from local conditions in the Combeima valley. The expected damage caused by landslides for different projected precipitation change levels $\Delta$ relative to a baseline ( $\Delta=0$ ) is presented on Fig. 4.

To get a better insight into the system, we divide the entire adaptation capacity of a EWS into internal and external adaptation capacities. The former is about changing internal rules e.g. conditions for issuance of an evacuation order, the latter is about changing the key characteristics of the EWS e.g. improving spatio-temporal resolution of rainfall measurements.

Internal and external adaptation capacities of a landslide EWS for our case study in Colombia are illustrated in Fig. 5 and Fig. 6 respectively. Note that negative values of $\Delta$ represent precipitation reduction and lead to smaller number of landslides and consequently reduction of losses e.g. zero expected losses for $\Delta=-0.2$ (Fig. 6). When the rainfall measurement error (RME) is fixed, only evacuation threshold is being adjusted to respond to a changed precipitation. The sensitivity of the EWS efficiency to that threshold adjustment is shown in Fig. 5. Here one may see relative loss reduction of adjusted EWS compared to unadjusted EWS: $\left(L_{u}-L_{a}\right) / L_{u}$, where $L_{u}$ are expected losses for unadjusted 
EWS and $L_{a}$ are those for adjusted EWS. The relative loss reduction is in fact moderate to fairly significant (10\%-25\%) for a combination of moderate precipitation change ( $\Delta=0.05$ or $\Delta=0.1$ ) and high precision EWS (RME $<0.15)$. For a less precise EWS (RME $>0.2)$ the efficiency gain due to adjusted evacuation threshold becomes negligible and comparable to the graph fluctuations of about $5 \%$ that are due to Monte-Carlo simulation assessment errors of the model. The efficiency gain is also very small (about 5\%) for an extreme precipitation increase of $\Delta=0.2$, indicating nearly no EWS internal capacity in that case independent of how precise the EWS is (all values of RME).

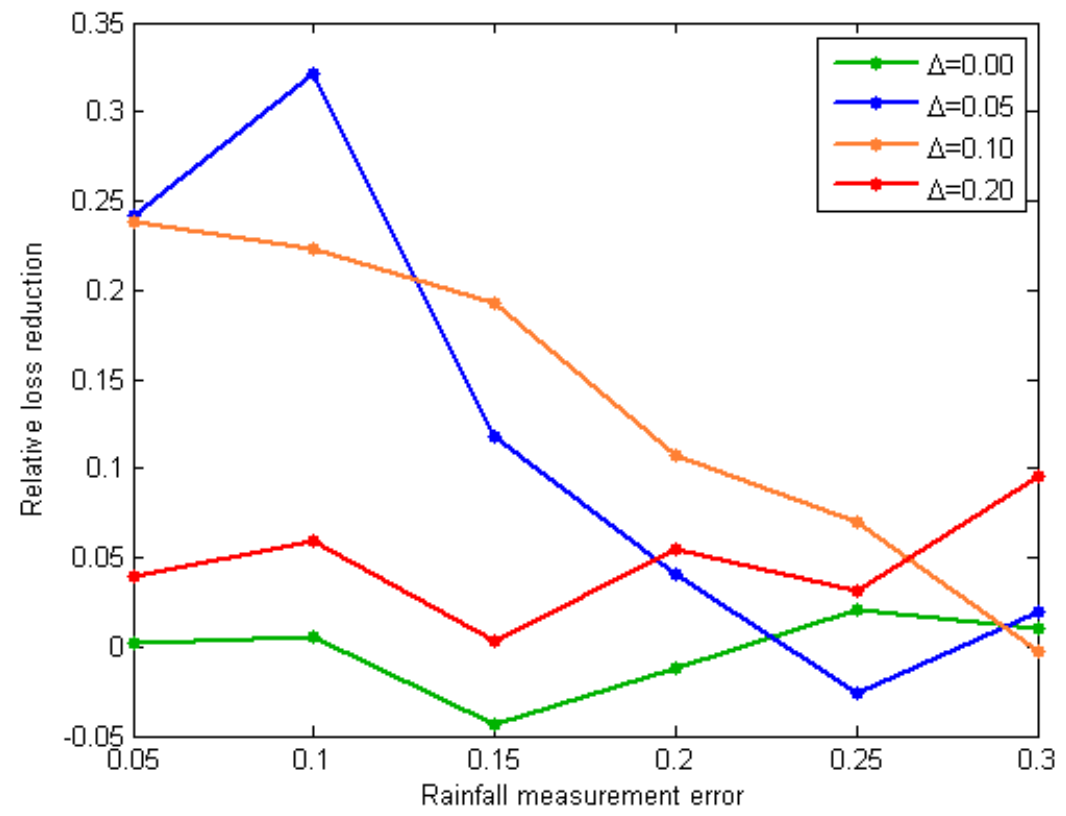

Figure 5.Indication of an internal adaptation capacity of a EWS. Here the internal adaptation capacity refers to evacuation threshold adjustment.

We explore the influence of the rainfall measurement error (RME) on a EWS that was preliminary adjusted in terms of evacuation threshold for a fixed value of $\Delta$. The results are presented on Fig. 6. Exploring it one may notice the high importance of RME improvement for EWS adaptation purposes. When going from $\mathrm{RME}=0.3$ and $\Delta=0$ (baseline) to a combination of extreme precipitation change scenario of $\Delta=0.2$ and substantially improved LS EWS with a RME=0.05, the EWS efficiency is even slightly increased (expected loss decreased). The RME improvement (that corresponds to external adaptation capacity) seems to have a bigger potential for adapting a EWS as compared to evacuation threshold adjustment only. Looking at Fig. 6 one may see that relative loss reduction of RME-improved EWS over initial EWS even for an extreme precipitation increase $(\Delta=0.2)$ may well be around (2.7$1.1) / 2.7 \approx 60 \%$ (for $\mathrm{RME}=0.3$ and 0.05 ) that is substantially bigger than the same relative values for only threshold adjustment, see Fig. 5.

\section{Discussion and model limitations}

The projection of future changes in landslide activity driven by climate change is uncertain. The few existing hydrological and slope stability modeling studies indicate a strong influence of local site 
conditions, resulting in scenarios of both, increase or decrease of landslide activity. Most climate models, however, indicate an increase of frequency and/or magnitude of extreme precipitation and temperature events during the 21st century (Kharin et al., 2007; Kyselỳ and Beranová, 2009). Depending on the magnitude of this increase, and other climatically or anthropogenically driven changes, an increase in landslide activity may be projected (Jakob and Lambert, 2009).

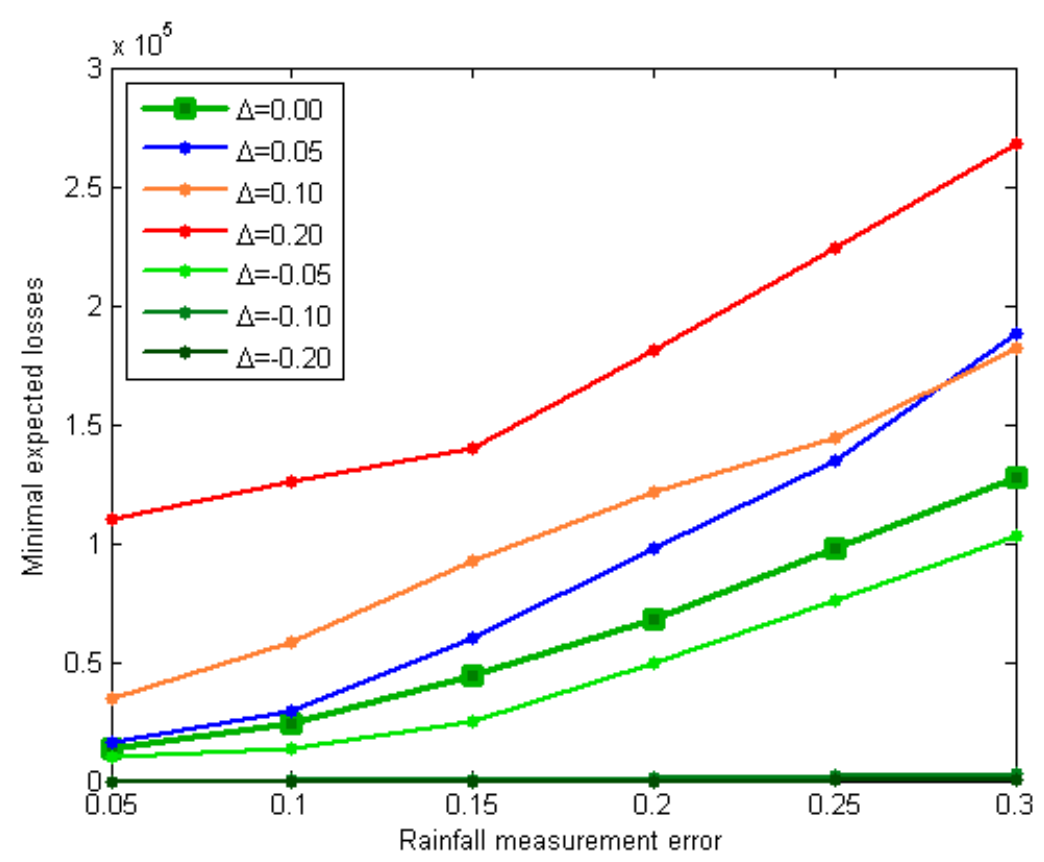

Figure 6.Indication of an external adaptation capacity of a EWS. Here external adaptation capacity refers to rainfall measurement error (RME) improvement.

From a theoretical point of view, an increase in extreme rainfall events is likely to increase the occurrence of shallow landslides and debris flows under otherwise unchanged conditions. However, although extreme precipitation events have increased in many regions of the world over the past decades, significant, let alone systematic, changes to landslide magnitude-frequency distributions remain to be detected. Reasons for this include incomplete or biased documentation of events that limit extraction of climatic signals because of the overprint of effects from recent changes in land-use or land-management (e.g. deforestation).

It is necessary to mention that there are a number of limitations pertinent to the described modeling approach and analysis of a EWS adaptation capacity. Some of the limitations are connected to the simplified way of modeling a EWS, the others are due to the lack of statistical data. A detailed discussion on that can be found in (Huggel et al. 2010). The approach based on stochastic optimization with application to variable rainfall measurement errors and relevant evacuation thresholds implemented in our model has barely been applied to landslide problems so far. It links measured environmental parameters such as rainfall with landslide consequences and damage in one integrated model. The numerical EWS model has clear limitations but also significant potential that may lead well beyond what we have presented here.

Another set of limitations stems from the modeling of projected climate change. Increased precipitation most likely will result in an increased number of landslides. Yet the assumption of a stationary system in terms of a constant triggering threshold is probably not correct beyond certain level of climate change that may also involve vegetation change and related effects on slopes stability. Another related difficulty for a landslide EWS are non-landslide triggering rainfall events whose intensity-duration 
relation exceeds the threshold and thus would require issuing an alarm. Recent studies using different rainfall thresholds with respective exceedance probabilities are an important progress but do not fully address the problem of non-landslide rainfall events (Brunetti et al. 2010). Soil mechanics models, on the other hand, are not expected to significantly reduce these uncertainties for a EWS, given the high spatial variability of soil and rainfall conditions.

One of the principal limitations of any EWS is that beyond some critical risk threshold it is not efficient anymore and other measures need to be implemented do adequately address changed risk levels. Depending on available local or natural resources for risk reduction, structural measures (e.g. dams) and/or relocation of endangered assets, including population, may be alternative or complementary options to a EWS.

Eventually, a model limitation arises from not explicitly considering human response within the landslide EWS. For instance, the willingness of the local population to evacuate might decrease with repeated false alarms (Dash and Gladwin 2007). Communication of the early warning procedures and uncertainties to people are crucial (Dow and Cutter 1998), but in general more research is needed to reasonably implement such aspects in a numerical model. Experiences with the recently implemented EWS in the Combeima region in Colombia show that the degree of information and knowledge on the EWS by local people are crucial for the success of the system. Population only accepts and supports the system, and takes according action if they understand why the EWS is helpful for them and if they perceive it as a useful tool to reduce risks. Discussion with and training for different social groups of the population are therefore an important part of the EWS in the Combeima region.

\section{Conclusion}

Colombia is one of the particularly badly affected countries due to predominantly rugged terrain and tropical rainfall conditions. In many areas landslide hazard zones overlap with residential zones and infrastructure. EWS are therefore important to reduce landslide risks, and in particular avoid casualties. Changing rainfall patterns may, however, pose an additional challenge to landslide EWS. Our studies indicate that for a climate change unadjusted EWS damage costs may in fact rise considerably with higher rainfall in the future. There seems to be a higher adaptation potential in terms of improving the rainfall observations than internally adjusting evacuation procedures (such as adjusting evacuation thresholds). Given the current limitation in physical understanding of landslide triggering processes and related uncertainties in predicting landslide occurrence, improved rainfall monitoring (and more generally: environmental monitoring) can be considered an important part of the adaptation strategy for future climate change.

\section{Acknowledgments}

The research leading to these results has received funding from the European Union's Seventh Framework Programme (FP7/2007-2013) under Grant Agreement no. 212535 (CC-TAME, www.cctame.eu). Further important support comes from the Swiss Agency for Development and Cooperation. Collaborations with the Comité Regional para la Prevención y Atención de Desastres del Tolima (CREPAD), the Colombian Dirección General de Prevención y Atención de Desastres (DPAD), the Instituto de Hidrología, Meteorología y Estudios Ambientales (IDEAM), the Instituto Colombiano de Minería y Geología (INGEOMINAS), the Corporación Regional del Tolima (CORTOLIMA), and the Colombian Red Cross are much appreciated. 


\section{References}

Basher, R. (2006) Global early warning systems for natural hazards: systematic and people-centered. Philosophical Transactions of the Royal Society A, 364: 2167-2187.

Brunetti, MT., Peruccacci, S., Rossi, M., Luciani, S., Valigi, D., Guzzetti, F., (2010) Rainfall thresholds for the possible occurrence of landslides in Italy.Natural Hazards Earth System Sciences, 10(3): 447458.

Caine, N. (1980) The rainfall intensity-duration control of shallow landslides and debris flows. Geogr Ann A 62: 23-27

Christensen, J.H., B. Hewitson, A. Busuioc, A. Chen, X. Gao, I. Held, R. Jones, R.K. Kolli, W.-T. Kwon, R. Laprise, V. Magaña Rueda, L. Mearns, C.G. Menéndez, J. Räisänen, A. Rinke, A. Sarr and P. Whetton (2007) Regional Climate Projections. In: Climate Change 2007: The Physical Science Basis. Contribution of Working Group I to the Fourth Assessment Report of the Intergovernmental Panel on Climate Change [Solomon, S., D. Qin, M. Manning, Z. Chen, M. Marquis, K.B. Averyt, M. Tignor and H.L. Miller (eds.)]. Cambridge University Press, Cambridge, United Kingdom and New York, NY, USA.

Dash, N. Gladwin, H. (2007) Evacuation decision making and behavioral responses: Individual and household. Natural Hazards Review, 8: 69-77.

Dow, K, Cutter, S (1998) Crying wolf: repeat responses to hurricane evacuation orders. Coastal Management, 26: 237-252.

Glade, T., Crozier, M., Smith, P. (2000) Applying probability determination to refine landslide-triggering rainfall thresholds using an empirical "antecedent daily rainfall model”.PureApplGeophys157: 10591079.

Godoy BF, Guerrero MV., Hoyos C, Núñez TA (1997) Análisis de la vulnerabilidad de líneas vitales y edificaciones estratégicas en la zona rural de la cuenca del Río Combeima - Municipio de Ibagué, Tolima - Evento avalancha, detonante lluvia, 139 pp. Universidad del Tolima, Facultad de IngenieríaForestal.

Guzzetti, F., Perucacci, S., Rossi, M., Stark, CP. (2008) The rainfall intensity-duration control of shallow landslides and debris flows: an update. Landslides 5: 3-17.

Huggel, C., Khabarov, N., Obersteiner, M., Ramírez, JM (2010) Implementation and integrated numerical modeling of a landslide early warning system: a pilot study in Colombia.Natural Hazards, 52: 501518.

Iverson, RM, Reid, ME, LaHusen, RG (1997) Debris-flow mobilization from landslides.Annual Review of Earth and Planetary Sciences 25: 85-138.

Jakob, M. Lambert, S. (2009): Climate change effects on landslides along the southwest coast of British Columbia. Geomorphology 107(3-4): 275-284.

Kharin, V., Zwiers, F., Zhang, X., Hegerl, G. (2007) Changes in temperature and precipitation extremes in the IPCC ensemble of global coupled model simulations. Journal of Climate 20: 1419-1444.

Kyselỳ, J., Beranová, R., (2009) Climate-change effects on extreme precipitation in central Europe: uncertainties of scenarios based on regional climate models. Theoretical and Applied Climatology 95(3): 361-374.

Marengo, JA., Jones, R., Alves, LM., Valverde, MC., (2009) Future change of temperature and precipitation extremes in South America as derived from the PRECIS regional climate modeling 
system. International Journal of Climatology, 29(15): 2241-2255.

Petley, DN, Higuchi, T, Petley, DJ, Bulmer, MH, Carey J. (2005) Development of progressive landslide failure in cohesive materials. Geology, 33: 201-204.

Sorensen, JH (2000). Hazard warning systems: review of 20 years of progress. Natural Hazards Review, 1 (2): 119-125.

Terlien, MTJ (1998) The determination of statistical and deterministic hydrological landslide triggering thresholds. Environmental Geology, 35: 124-130.

Thouret, J-C, Cantagrel, JM, Robin, C, Murcia, A, Salinas, R, Cepeda, H (1995) Quaternary eruptive history and hazard-zone model at Nevado del Tolima and Cerro Machin volcanoes, Colombia, $J$ VolcanGeotherm Res,66: 397-426.

Uppala, SM et al. (2005) The ERA-40 re-analysis.Quarterly Journal of the Royal Meteorological Society, 131, 612: 2961-3012.

Zschau, J, Küppers, AN (eds.) (2003). Early warning systems for natural disaster reduction. Berlin, Springer, pp. 834. 